\section{A BASIC program for multiple regression}

\section{SUZANNE V. BORYS and JAMES G. CORRIGAN E. R. Johnstone Training and Research Center Bordentown, New Jersey 08505}

MULTREG computes regression analyses for two or more independent variables (IVs). The program is currently dimensioned for eight IVs and $\mathrm{N}=200$, and it requires about $9 \mathrm{~K}-12 \mathrm{~K}$ of memory, depending on the size of $\mathrm{N}$. If more memory is available, the program can easily be redimensioned to increase the number of IVs and $\mathrm{N}$. Computational procedures are based on those described by Kerlinger and Pedhazur (1973).

Input. Data are entered through the use of DATA statements. The user must supply the total number of variables, the total $\mathrm{N}$, and the scores for each subject. The user must also redimension the arrays in Line 30 of the program only for the exact number of IVs employed, due to the nature of the matrix inversion command. Instructions for data input and redimensioning are included in the documentation.

Output. Output is directed to a line printer and consists of all correlations among the IVs, all correla-

Development of this program was supported by Grant HD 07329 from the National Institute of Child Health and Human Development. tions between the dependent variable $\mathrm{Y}$ and the IVs, the summary table (which includes the squared multiple correlation), the unstandardized and standardized betas, the Y-intercept, the multiple correlation, the original and predicted $Y s$, and a table of standard errors and $t$ ratios for the beta weights.

Limitations. There is no separate program routine to invert the correlation matrix. If the matrix is noninvertible, the INV command that is used in this program causes an error message to be displayed, and program execution is terminated.

Language and Computer. The programs are written in BASIC and have been implemented on a WANG system $2200-\mathrm{B}$ with $32 \mathrm{~K}$ of memory. This particular form of BASIC includes such nonstandard commands as SELECT PRINT and INV.

Availability. Program listings and documentation are available for $\$ 2$ (to cover copying and mailing costs) from Suzanne Borys, Research Department, E. R. Johnstone Training and Research Center, Bordentown, New Jersey 08505. Make checks payable to: Research Discretionary Acct., Johnstone Ctr.

\section{REFERENCE}

Kerlingen, F., \& Pedhazur, E. Multiple regression in behavioral research. New York: Holt, Rinehart, \& Winston, 1973.

(Accepted for publication January 10, 1981.)

\title{
ERRATUM
}

Ray, R. L., Emurian, H. H., \& Wurster, R. M. COMOV: A program for the analysis of the relationship between two time series. Behavior Research Methods \& Instrumentation, 1980, 12 (4), 479-480. Page 479: Equations 4 and 5 should be modified to read as follows:

$$
\begin{aligned}
& \theta_{\mathrm{I}}=\mathrm{G}_{\mathrm{I}} /(\mathrm{N}-\mathrm{I})-\left[(\mathrm{A}+\mathrm{B})^{2} / \mathrm{N}^{2}\right] \\
& \mathrm{E}_{\mathrm{I}}=\mathrm{H}_{\mathrm{I}} /(\mathrm{N}-\mathrm{I})-\left[(\mathrm{A}+\mathrm{C})^{2} / \mathrm{N}^{2}\right]
\end{aligned}
$$

